\title{
Caracteres Humanos Herdados Utilizados no Ensino de Genética em Livros Didáticos
}

\author{
Cléia Rosani Baiotto \\ Élgion Lucio da Silva Loreto
}

\begin{abstract}
RESUMO
Caracteres hereditários humanos vêm sendo progressivamente incluídos na contextualização dos padrões de herança no Ensino Médio com o objetivo de aproximar o cotidiano do aluno, tornando o ensino mais interessante, motivador e significativo. Informações equivocadas, com erros, desvios e mesmo simplificações com relação ao padrão de herança desses caracteres podem comprometer o ensino e levar a um descrédito da informação científica. Este estudo teve por objetivo levantar e analisar a utilização desses caracteres como forma de contextualizar os padrões de herança nos livros didáticos referências para o Ensino Médio em Biologia (PNLEM/2012). Observa-se uma preferência em utilizar caracteres humanos externos e facilmente identificáveis. No entanto, diferentes equívocos são relatados na utilização desses caracteres, sendo que os que mais comprometem o ensino são os erros conceituais e os desvios com relação à descrição dos textos de referência, que podem comprometer o ensino em decorrência dos equívocos implícitos nessas simplificações, visto que esses traços podem ser facilmente observáveis em si mesmo e em seus familiares.
\end{abstract}

Palavras-chave: Traços Hereditários. Ensino de Genética. Contextualização. Caracteres Humanos.

\section{Inherited Human Characters Used in Teaching Genetics in Textbooks}

\begin{abstract}
Human hereditary characters have been progressively included in the contextualization of inheritance patterns in high school with the aim of approaching the students daily lives, making teaching more interesting, motivating and meaningful. Misinformation, with errors, deviations and even simplifications with respect to the pattern of inheritance of these characters can compromise teaching and lead to a discredit of scientific information. This study aimed to survey and analyze the use of these characters as a way of contextualizing the patterns of inheritance in reference textbooks for the study of Biology in High School (PNLEM / 2012). It is observed a preference in using external and easily identifiable human characters. However, different misconceptions are reported in the use of these characters, being that the ones that most compromise teaching are conceptual errors and deviations from the description of reference texts that may compromise
\end{abstract}

Cléia Rosani Baiotto é Doutora em Educação em Ciências: Química da Vida e Saúde, Mestre em Genética e Biologia Molecular (UFRGS), graduada em Ciências Biológicas (UFSM), professora no Centro de Ciências da Saúde e Agrárias da Universidade de Cruz Alta, Cruz Alta, RS. E-mail: cbaiotto@unicruz.edu.br

Élgion Lucio da Silva Loreto é Doutor em Genética e Biologia Molecular (UFRGS), professor associado do Departamento de Bioquímica e Biologia, Universidade Federal de Santa Maria, Santa Maria, RS. E-mail: elgionl@gmail.com

Recebido para publicação em 10 maio 2018. Aceito, após revisão, em 20 jul. 2018.

DOI: https://doi.org/10.17648/acta.scientiae.v20iss4id4095.

\begin{tabular}{|l|l|l|l|l|l|}
\hline Acta Scientiae & Canoas & v.20 & n.4 & p.593-609 & jul./ago. 2018 \\
\hline
\end{tabular}


teaching due to the implicit misunderstandings in these simplifications, since these traits can be easily observed in themselves and in their relatives.

Keywords: Hereditary Traits. Teaching of Genetics. Contextualization. Human Characters.

\section{INTRODUÇÃO}

Compreender os mecanismos associados à transmissão hereditária das características humanas e a possível diversidade de suas expressões, tanto nas condições normais como na gênese de várias doenças, é de significativa importância para que o indivíduo possa fazer uso de forma plena do que lhe é ofertado em profusão pela sociedade tecnológica atual, seja como alimentos, fármacos ou serviços especializados que vão de testes de identificação a uma medicina individualizada e preventiva.

O conhecimento básico sobre os padrões de herança e os mecanismos moleculares da variabilidade humana desenvolvidos na escola têm importantes implicações culturais e sociais, ao mesmo tempo em que permitem minimizar preconceitos com relação às doenças hereditárias e variações normais, como, por exemplo, a cor da pele.

As novas descobertas relativas à genética molecular humana, somadas à velocidade de divulgação na mídia, têm ampliada a importância dada a esses temas no ensino. Assim como têm determinado uma maior inclusão dos conteúdos de genética humana no Ensino Médio (Melo \& Carmo, 2009). Nesse sentido, documentos oficiais (Brasil, 2000) também vêm reforçando a necessidade de inserção da genética no ensino formal de modo atualizado e objetivando a formação cidadã acima mencionada.

Mesmo recente, o ensino de Genética já é foco de inúmeros estudos relacionados às dificuldades. Entre elas podem ser apontados o excesso de memorização associado à falta de contextualização (Soares, Pinto, \& Rocha, 2005; Moura et al., 2013), a compreensão inadequada da terminologia e concepções errôneas sob o ponto de vista científico (Paiva \& Martins, 2005; Scheid \& Ferrari, 2006; Malafaia et al., 2010; Infante-Malachias et al., 2010) que se somam ao distanciamento entre a produção do conhecimento e a necessidade de atualização dos materiais didáticos (Loreto \& Sepel, 2003).

Para o ensino dos padrões de herança são apresentados, geralmente, como exemplos as diferenças nas sementes de ervilha, a cor dos olhos de moscas, chifres em bovinos e outros que, apesar do apelo histórico e da exatidão científica, são distantes da realidade do aluno, por isso não despertam interesse sobre a temática (Baiotto, Sepel, \& Loreto, 2016).

É consenso que aprender exige conhecimento prévio (Ausubel, 2003), motivação e interesse (Vigostski, 2001), além de que essa disposição para aprender integra pensamentos, sentimentos e ações (Novak, 2011). Do mesmo modo, tudo aquilo que não é tomado como significativo tende a ser abandonado (La Rosa et al., 1998). Nesse sentido, mais recentemente, os professores estimulados pela curiosidade natural do aluno, pelo fato de a Genética estar na mídia e pelas reiteradas sinalizações dos documentos oficiais sobre a necessidade de contextualizar o ensino, começaram a ver na utilização de 
caracteres humanos um modo de contextualização dos padrões de herança e uma forma de motivar a aprendizagem em Genética. A utilização de caracteres observáveis em si, em seus familiares, ou em conhecidos entra nesse processo como uma tentativa de um ensino mais interessante, motivador e significativo.

Dessa forma, a inclusão de novos temas de genética humana no currículo e de exemplos de padrões de herança humanos para temas gerais, além de proporcionar essa melhor contextualização, resgata questões culturais atreladas à transmissão das características, desperta a curiosidade natural e desencadeia uma maior compreensão desses temas, inserindo os alunos de forma mais efetiva no processo de aprendizagem, visto que se constituem no próprio objeto de estudo (Camargo \& Infante-Malachias, 2007).

Contextualizar o ensino de genética com a utilização de caracteres humanos está de certa forma ligado às diferentes concepções de contextualização do ensino de Kato e Kawazaki (2011) onde relacionam ao cotidiano do aluno, à(s) disciplina(s) escolar(res) e ao contexto histórico, social e cultural, inserindo o contexto de vivência dos alunos no contexto de aprendizagem. Lima e colaboradores (2000) acrescentam que "a contextualização do ensino ocorre quando são considerados os conhecimentos prévios e o cotidiano dos alunos". Melo e Carmo (2009) também reforçam o aspecto positivo da inserção de caracteres humanos como forma de contextualização no ensino de genética.

Entre os caracteres humanos utilizados nesse sentido e descritos por autores como Badzinski e Hermel (2015) ao avaliarem imagens utilizadas nos livros de Biologia, estão o modo de cruzar as mãos, a capacidade de enrolar a língua, a forma do polegar, a implantação dos cabelos na cabeça e o lóbulo da orelha.

Paralelamente, a utilização do livro didático como suporte no planejamento, na organização e execução das aulas é ainda um dos principais recursos do professor no Ensino Médio. É considerado ainda por muitos professores como a principal ou única fonte de textos utilizados em sala de aula (Gambarini \& Bastos, 2006). A importância assumida pelo livro didático no ensino ao longo dos anos levou a diversas avaliações com relação à qualidade (Pimentel, 1998), seu papel na escola contemporânea (Bittencourt, 2004) e utilização de imagens (Badzinski \& Hermel, 2015) e em relação a conceitos específicos de Genética (Santos \& El Hani, 2009; Franzolin \& Tolentino-Neto; Bizzo, 2014; Franzolin \& Bizzo, 2015).

Cabe destacar que essa utilização se amplia a partir da aprovação do Plano Nacional do Livro Didático (PNLD) em 2006, com o objetivo de proporcionar um material suplementar de qualidade, quando passou a garantir o atendimento para todos os alunos do Ensino Médio da rede pública, com a distribuição dos livros didáticos de todas as disciplinas básicas do currículo escolar (Brasil, 2008). Questões importantes além dos aspectos conceituais norteiam o processo de avaliação e escolha dos livros didáticos que são indicados e distribuídos pelo PNLD. Entre elas, os livros devem contextualizar o conteúdo, aproximando este do cotidiano do aluno, utilizar recursos visuais atrativos que façam com que o aluno pense sobre o que está escrito, indicar sites educativos, permitindo 
a exploração do ambiente virtual, e estimular o trabalho científico através da sugestão de atividades práticas (Brasil, 2011).

Muitos desafios ainda precisam ser superados para que o livro didático se aproxime mais efetivamente do seu propósito. Um desses desafios está relacionado à transposição didática do conhecimento acadêmico para o livro didático e deste para a sala de aula, considerados por Chevallard (1997) como essencial para que o conhecimento científico chegue ao aluno. A transposição do conhecimento científico de forma mais simplificada para o livro didático, visando tornar o conhecimento mais acessível ao aluno, é descrita por Franzolin e Bizzo (2009) como laxismo. Estes autores, ao analisarem as divergências encontradas na transposição de uma bibliografia de referência para livros didáticos, encontraram nos livros brasileiros generalizações de ocorrência, seguidas dos desvios conceituais, em maior quantidade quando comparados a livros norte-americanos de mesma fase. Posteriormente, Franzolin, Tolentino-Neto e Bizzo (2014) destacaram uma grande incidência de generalizações em temas específicos como a meiose, que, segundo os autores, determinam um distanciamento do conhecimento veiculado nos livros de referência.

A forma de abordagem de alguns conteúdos de Genética nos livros didáticos pode dificultar a relação entre vários conceitos importantes, como, por exemplo, os descritos por Ferreira e Justi (2005) com relação aos conceitos da molécula de DNA, genes e cromossomos e fases em que se estudam esses conceitos nos livros de Química e Biologia. Do mesmo modo, erros conceituais comprometem o ensino, como pode ser observado em Bizzo (2009), o qual descreve situações que se repetem em algumas obras, de conceitos apresentados fundamentados em premissas não aceitas pela comunidade científica e que estão baseados em modelos falsos e conhecimentos adaptativos no contexto escolar. Franzolin e Bizzo (2015), ao analisarem livros do PNLD, preferem abordar todas as divergências observadas na transposição didática encontradas nos livros didáticos como desvios conceituais. Justificam a escolha por essa denominação considerando que eles passam por uma avaliação prévia.

Mesmo assim, inconsistências, desvios e erros conceituais têm sido observados nos livros didáticos com relação aos caracteres humanos utilizados como exemplos de padrões de herança, que, por consequência, são repassados aos alunos. Conteúdos apresentados de forma equivocada e com excesso de simplificações na sua transposição didática têm implicações científicas e culturais importantes. A contextualização atrelada à utilização desses caracteres, quando apresentados com erros, desvios conceituais ou simplificações, pode gerar problemas associados a questões de familiaridade, grau de parentesco, entre outros. Pode também levar ao descrédito na informação científica, quando o aluno percebe, por exemplo, na inconformidade do que ele observa em sua família com informações simplificadas de que "pais de olhos claros não podem ter filhos de olhos castanhos" e de que "pais canhotos não podem ter filhos destros" (Baiotto, Sepel, \& Loreto, 2016).

Dessa forma, os escassos referenciais para o tema proposto e as inconsistências observadas nos livros didáticos, que se somam aos potenciais prejuízos sociais que um ensino contextualizado de forma inadequada pode causar nos estudantes, justificam esta 
proposta. Este estudo teve por objetivo levantar e analisar a utilização de caracteres humanos como forma de contextualizar os padrões de herança nos livros didáticos referências para o Ensino Médio em Biologia.

\section{METODOLOGIA}

A investigação se caracterizou quanto aos objetivos e o procedimento de coleta dos dados como exploratório e documental; com análise da utilização dos caracteres humanos na contextualização dos padrões de herança e na avaliação do contexto em que esses exemplos se inserem nos livros didáticos, referências para o Ensino Médio em Biologia.

A escolha dos livros para a análise teve como referência o Programa Nacional do Livro Didático para o Ensino Médio (PNLEM) (Brasil, 2011). Os oito livros destacados no Guia de Livros Didáticos do PNLD 2012 - Biologia (Quadro 1)foram avaliados com relação à utilização dos caracteres humanos e identificados no texto como L1, L2 até L8.

Quadro 1. Lista de livros - Guia de livros didáticos: PLND2012: Biologia/Ciências da Natureza e suas Tecnologias.

\begin{tabular}{|c|c|c|c|}
\hline \multicolumn{2}{|r|}{ Nome da Obra } & Autor(es) & Editora \\
\hline L1 & Biologia Hoje & $\begin{array}{l}\text { Fernando Gewandsnajder } \\
\text { Sérgio de Vasconcellos } \\
\text { Linhares }\end{array}$ & Ática \\
\hline L2 & Biologia & $\begin{array}{l}\text { Gilberto Rodrigues Martho } \\
\text { José Mariano Amabis }\end{array}$ & Moderna \\
\hline L3 & Ser Protagonista Biologia & $\begin{array}{l}\text { André Catani } \\
\text { Antonio Carlos Bandouk } \\
\text { Elisa Garcia Carvalho } \\
\text { Fernando Santiago dos Santos } \\
\text { João Batista Vicentin Aguilar } \\
\text { Juliano Viñas Salles Maria } \\
\text { Martha Argel de Oliveira } \\
\text { Tatiana Rodrigues Nahas } \\
\text { Silvia Helena de Arruda } \\
\text { Campos Virgínia Chacon }\end{array}$ & Edições SM \\
\hline L4 & Bio & $\begin{array}{l}\text { Sônia Lopes } \\
\text { Sérgio Rosso }\end{array}$ & Saraiva \\
\hline L5 & Biologia & $\begin{array}{l}\text { César } \\
\text { Sezar } \\
\text { Caldini }\end{array}$ & Saraiva \\
\hline L6 & Biologia & $\begin{array}{l}\text { Pezzi } \\
\text { Gowdak } \\
\text { Mattos }\end{array}$ & FTD \\
\hline L7 & Biologia para a Nova Geração & $\begin{array}{l}\text { V. Mendonça } \\
\text { J. Laurence }\end{array}$ & Nova Geração \\
\hline L8 & Novas Bases da Biologia & Nélio Bizzo & Ática \\
\hline
\end{tabular}

Brasil (2011). 
A coleta de dados para a análise documental se deu através de uma ficha de avaliação que considerou os seguintes aspectos: caracteres humanos tomados como exemplos pelos autores e o número de citações associadas a esse caráter, tanto no texto como nos exercícios. Assim, buscou-se identificar os conceitos utilizados para cada termo que representasse um padrão de herança e sinonímias. Foram consideradas para a análise: a herança monogênica e poligênica, autossômica e ligada ao X e formas correlatas, herança dominante, recessiva e sem dominância, interação genética, alelos múltiplos e grupos sanguíneos, comparados a um referencial teórico (Stracham \& Read, 2013; Borges-Osório \& Robinson, 2013) e ao banco de dados OMIM (2017). A análise da frequência com que os caracteres foram encontrados nas obras analisadas foi expressa em percentuais e representada em gráficos.

A descrição dos padrões de herança e dos caracteres humanos tomados como exemplos pelos autores dos livros analisados determinou a utilização de agrupamentos por similaridades, levando em conta sua pertinência e intenções da investigação, seguindo Bardin (2011), reunidos em quatro grupos: erro conceitual, desvio conceitual em relação à descrição, simplificação e descrição apropriada, definidos como:

- Erro conceitual - informação falsa e que não confere com referência utilizada.

- Desvio em relação à descrição (equívocos) - quando os exemplos utilizados na obra diferem significativamente em relação ao conceito descrito.

- Simplificação - a característica é informada na obra com um dado padrão de herança (geralmente multifatorial), mas utilizada como um exemplo de outro padrão (geralmente mendeliano simples). A simplificação na abordagem é assumida explicitamente pelos autores.

- Descrição apropriada - categoria em que o conceito está de acordo com a referência utilizada na avaliação.

Cabe destacar que determinados padrões de herança necessitaram ser enquadrados em diferentes categorias mesmo dentro da mesma obra. Toda descrição dos caracteres humanos foi comparada às referências já descritas. Problemas associados à transposição didática ou de falta de atualização foram evidenciados. Do mesmo modo, foram coletadas ressalvas ou observações dos autores que pudessem alertar os alunos e os professores quanto a erros nas concepções de herança apresentadas.

\section{RESULTADOS E DISCUSSÃO}

Com relação à frequência dos caracteres humanos hereditários utilizados como exemplos pelos autores nos oito livros didáticos na contextualização do ensino de Genética, destacam-se, variando de 10 a 75 citações, o lóbulo da orelha, o albinismo, a fibrose cística, a fenilcetonúria, o daltonismo, a hemofilia e a produção de aglutinogênios A e B e o fator Rh. Com quatro ou mais citações, estão os caracteres: acondroplasia, a sensibilidade ao PTC (feniltiocarbamida), a polidactilia, a habilidade para destro ou canhoto, o gene para 
Alzheimer precoce, a galactosemia, genes para altura, cor do olho e cor da pele. Podem ser incluídos ainda neste grupo a capacidade de enrolar a língua, a forma de implantação dos cabelos, a cor de olho e o fator MN.

Citadas com menor intensidade foram identificadas características como o ângulo formado ao dobrar o polegar, a forma de cruzar as mãos e cruzar os braços, a miopia, a transpiração excessiva, a mecha branca nos cabelos, presença de sardas, a queratose, a catarata congênita, Tay Sachs, o raquitismo, a Síndrome de Marfan, a Coreia de Huntington, o prognatismo mandibular, a adrenoleucodistrofia (ALD), a textura do cabelo, a hipertricose e o peso.

Separados em capítulos como "herança do sexo" " "herança dos grupos sanguíneos", encontram-se temas específicos de genética humana, e, nesse caso, os exemplos para contextualizar são obrigatoriamente relativos a caracteres humanos. Na herança recessiva ligada ao cromossomo X, citam-se, predominantemente, o daltonismo e a hemofilia, justificando o elevado número de citações desses caracteres. Na herança dos grupos sanguíneos não poderia ser diferente, toda a explicação e a contextualização se deram em função da herança dos principais fatores sanguíneos presentes na espécie humana, principalmente do sistema $\mathrm{ABO}$ e do sistema $\mathrm{Rh}$.

Quando consideramos separadamente as características relativas à herança autossômica monogênica, percebe-se uma preferência significativa em utilizar caracteres humanos próximos e facilmente identificáveis, como a ausência de pigmentação da pele (albinismo). Seguem, na preferência dos autores, doenças como a fibrose cística e a fenilcetonúria e traços hereditários como a forma do lóbulo da orelha, a sensibilidade ao PTC, a habilidade destro/canhoto e a forma de implantação dos cabelos (Figura 1). Tomando o livro Genética Molecular Humana como referência (Strachan \& Read, 2013), características mendelianas ou monogênicas podem ser atribuídas a um único par de lócus, localizados em autossomos ou no cromossomo $\mathrm{X}$ ou no $\mathrm{Y}$, podendo ser dominantes ou recessivos.

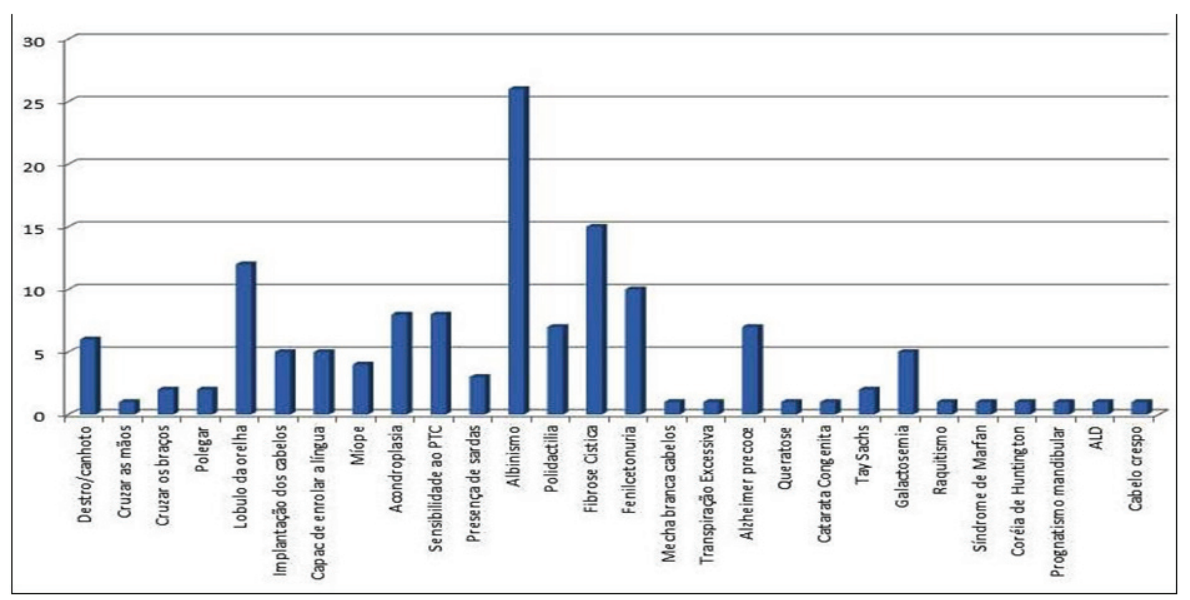

Figura 1. Número de citações de caracteres autossômicos monogênicos ${ }^{(*}$. (Baiotto, 2017).

* De acordo com os livros avaliados. 
Quando separados por obra, constata-se uma média de 3,2 $( \pm 1,97)$ nas citações dos traços identificados (Figura 2) entre as oito obras disponibilizadas no PNLD 2012 (BRASIL, 2011). Algumas características como o albinismo e a fibrose cística estão presentes na contextualização de praticamente todos os autores.

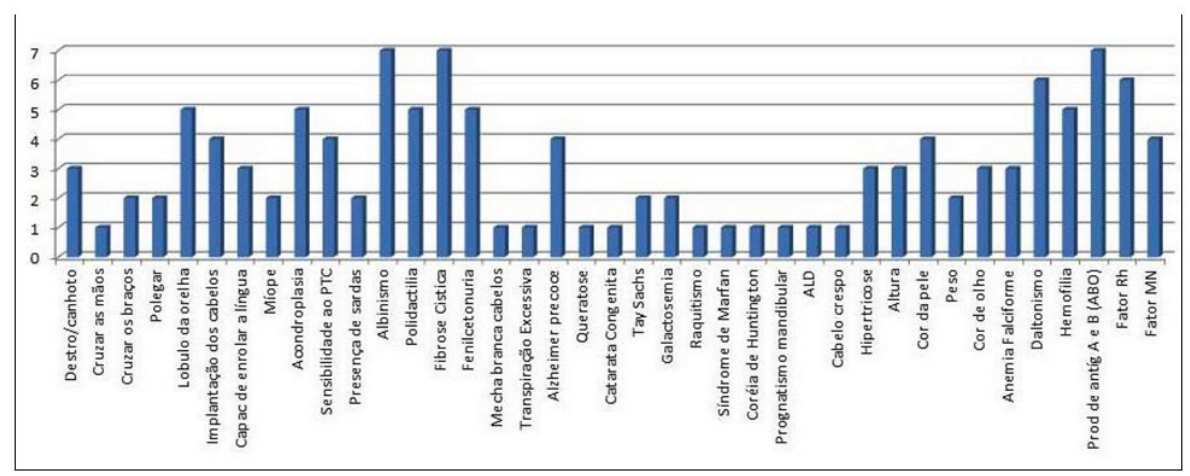

Figura 2. Número de livros que citam determinado exemplo de caráter humano ${ }^{(*)}$. (Baiotto, 2017)

*Total de oito livros no programa.

A fragmentação da análise dos caracteres humanos quanto à sua descrição como contextualização textual e como contextualização nos exercícios apresenta diferenças importantes. A maioria dos exemplos utilizados encontra-se na apresentação do conteúdo. Entretanto, o albinismo, a fibrose cística, a galactosemia, o gene para Alzheimer precoce, habilidade destro/canhoto e a cor do olho têm maior número de citações nos exercícios. Quando se considera a "herança do sexo" e dos "grupos sanguíneos", em razão de estar em capítulos específicos, essa diferença aumenta significativamente (Figura 3 e 4).

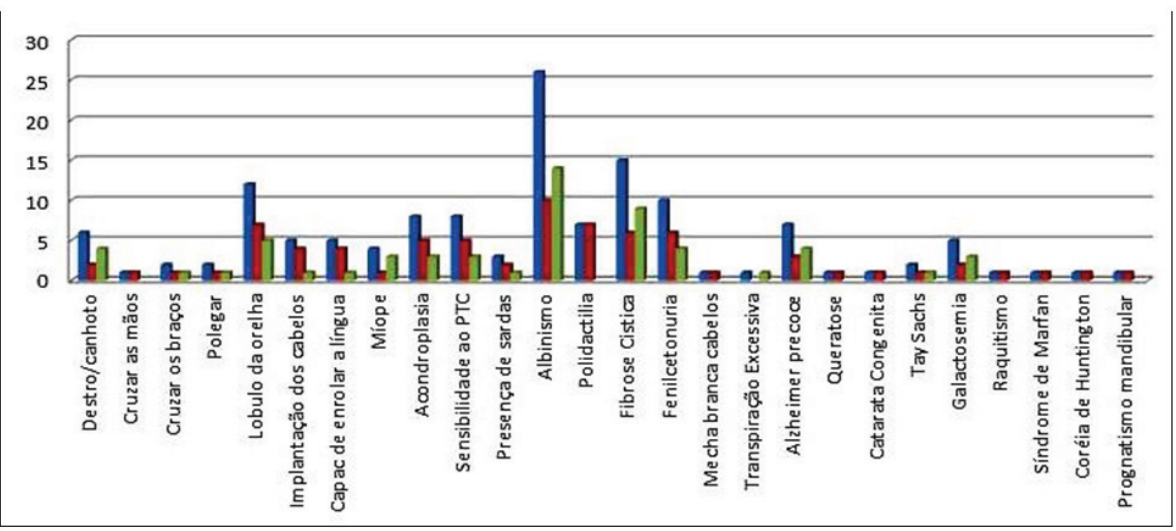

Eotal Citaçōes = Total Texto = Total Exerc

Figura 3. Número de citações de caracteres em relação à inserção no texto ou exercícios. (Baiotto, 2017) 


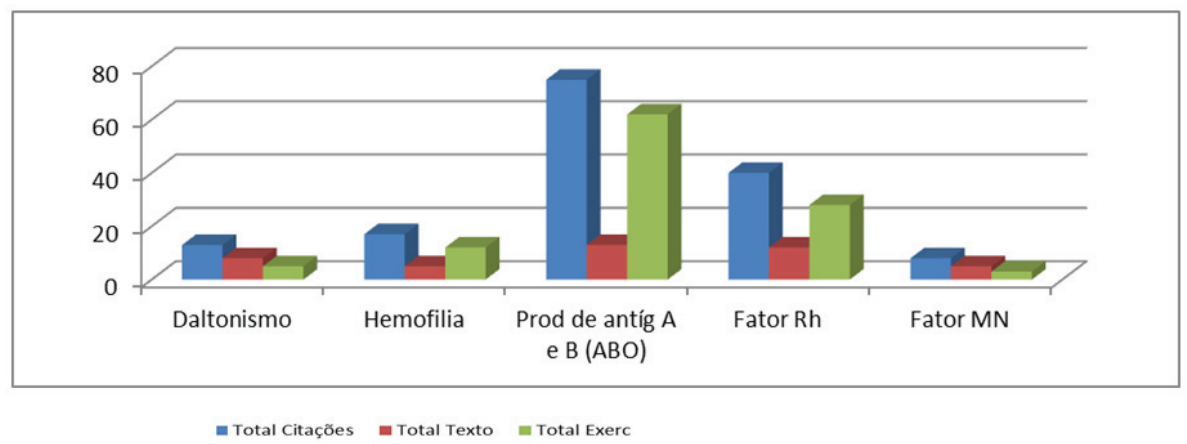

Figura 4. Número de citações de caracteres em relação a inserção no texto ou exercícios (continuação). (Baiotto, 2017).

O ensino de Genética no Brasil inicia com o mendelismo nas escolas de Agronomia em São Paulo na década de 1910 (Andrade, 2016). Ao final da década de 1950 e início de 1960, com a criação da Sociedade Brasileira de Genética (SBG) estimula-se a transferência dos conhecimentos de genética de drosófilas para estudos com genética humana. Inicia-se desta forma a constituição de departamentos de genética médica nas universidades, o que promove o início do ensino na área (Souza et al., 2013) e posteriormente nas escolas de Ensino Médio (Brasil, 2000).

Nessa situação, contextualizar pode aproximar o conteúdo formal (científico) do conhecimento trazido pelo aluno (não formal), para que o conteúdo escolar se torne interessante e significativo (Kato \& Kawazaki, 2011). Do mesmo modo, Lopes (2002) destaca a necessidade de envolver os aprendizes a partir de suas experiências e relacionadas ao seu contexto, de forma que se produza significado, favorecendo o processo de aprendizagem. Assim, a contextualização evocaria áreas, âmbitos ou dimensões presentes na vida pessoal, social e cultural, mobilizando competências cognitivas adquiridas e favorecendo a aprendizagem.

Esse modo de trabalhar o ensino de Genética está de acordo com os princípios e as condições de aprendizagem destacados por Ausubel (2003) com relação a: 1. Utilização de materiais potencialmente significativos como as características pessoais e, nesse caso, observáveis em si, nos familiares e nos colegas; e 2. Disposição para aprender, visto que desperta a curiosidade. Ausubel (2003) destaca que a aprendizagem se dá em cima do que se sabe, por isso, nesse caso, o conhecimento prévio pode ser um excelente precursor para a discussão do tema em sala de aula, como, por exemplo, a herança da cor dos olhos, do tipo de cabelo e da cor da pele.

Entretanto, questões culturais ou de senso comum, trazidas nesse contexto, podem dificultar ou desmotivar o ensino de Genética. Entre as informações disseminadas na população está a cor dos olhos, que vem de uma concepção de senso comum que pais de olhos claros não podem ter filhos de olhos escuros. Entende-se por escuro os olhos 
castanhos, e claros, azuis ou verdes. Esse consenso é desconstruído quando, no ensino de Genética, se atribui a esse caráter um padrão de herança poligênica (mais de um par de genes).

Situações diferenciadas podem ser vivenciadas pelo professor na contextualização acima. Primeiro, se o professor trabalhar na desconstrução de um conceito prévio de senso comum, vai encontrar dificuldades na contextualização, mas está ensinando da forma correta. Nessa perspectiva, a herança de cor dos olhos não pode ser usada para exemplificar herança monogênica, como muitas vezes é utilizada. Por outro lado, se o professor consente nessa perspectiva de pais de olhos verdes, recessivos, não podem ter filhos de olhos escuros, associando o caráter a um padrão monogênico, mesmo com a justificativa de simplificação do conteúdo, esse aluno vai encontrar problemas ao se deparar com situações cotidianas contrárias ao que aprendeu, o que pode levar a um descrédito no ensino e na ciência como um todo. Ademais, a aplicação desses conceitos equivocados pode levar a problemas familiares, relativos a questionamentos de paternidade. Estas e outras situações observadas na análise das obras que podem suscitar esses equívocos merecem atenção e são descritas a seguir.

O caráter cor dos olhos é abordado de modo muito diferenciado pelos autores dos livros didáticos disponíveis no PNLD/2012. É descrito de forma apropriada por seis autores (86,5\% dos sete que citam), de acordo com o referencial tomado como base (OMIM \#227220), quando afirmam se tratar de interação genética, herança determinada por mais pares de genes. Um deles (L1) menciona a necessidade de simplificar, utilizando apenas os padrões claros e escuros. Entretanto, quatro deles (L4, L5, L6 e L8) apresentam, em outras partes da obra, os fenótipos azuis e castanhos como herança monogênica, com dominância do castanho sobre o azul, caracterizando-se como um desvio em relação à descrição (dois nos exercícios e dois deles no texto e nos exercícios). Dessa forma, 67\% das obras que descrevem de forma apropriada esse padrão de herança fazem um emprego equivocado dessa característica nos exercícios ou em outras partes do texto.

O autor (L8), depois de utilizar a cor de olho de forma simplificada no capítulo de monoibridismo, descreve-o no capítulo de herança quantitativa como resultado da ação de três pares de genes, em que atribui a cor azul ao indivíduo albino (denominado como aa). Nesse caso, observa-se um erro conceitual bem importante. O autor L3 descreve de forma adequada, enfocando um padrão de herança complexa, sem detalhar o processo, assim como também não utiliza esse caráter como exemplo nos exercícios.

A incapacidade de sintetizar melanina (OMIM 203100 - albinismo oculocutâneo I) é atribuída à presença em homozigose de um alelo recessivo. Esse padrão de herança, embora descrito de forma apropriada em relação à referência por todos os autores, pode gerar confusão quando o autor simplifica o padrão e não menciona tratar-se de uma rota metabólica, pela qual mutações em genes diferentes, em pais albinos, permitem o nascimento de crianças com pigmentação normal.

A cor da pele é outro caráter atribuído à herança multifatorial, com a participação de mais pares de genes na produção do pigmento melanina e pela influência ambiental 
(OMIM \#227220). Cinco autores utilizam esse caráter como exemplo de herança poligênica, com descrição apropriada. No entanto, um deles associa a quantidade de melanina produzida com o gene responsável pela capacidade de produção, sugerindo que o indivíduo albino seja resultado de epistasia. De acordo com Strachan e Read (2013), a epistasia pode ser caracterizada como resultante da heterogeneidade de lócus, ou seja, decorrente da ação de mais pares de genes, no qual um deles pode controlar ou impedir a ação do outro, nesse caso, a produção de melanina. Vários problemas se observam aqui, a mistura da quantidade de melanina produzida com a capacidade de produção e a confusão que se cria ao identificar o indivíduo de pele branca como indivíduo albino, o que não confere, visto que o albinismo é a condição determinada pela incapacidade de produção do pigmento para todas as regiões do corpo (pele, cabelo, sobrancelhas, olhos etc.).

A capacidade de enrolar a língua (OMIM 189300) é considerada um padrão de herança simples, determinada por um par de genes, mas que ainda necessita de estudos mais efetivos. Os autores que descrevem esse padrão tratam-no de forma apropriada, e apenas um deles (L1) faz uma ressalva, descrevendo uma possível influência da aprendizagem devido à elevada discordância entre gêmeos.

A lateralidade (OMIM\#139900), também entendida como a habilidade que diferencia os indivíduos em destros e canhotos, é apontada mais recentemente como um padrão de herança multifatorial, ou seja, influenciada por componentes genéticos, culturais e ambientais. Estudos mais antigos relatados no OMIM destacam a lateralidade como um padrão de herança monogênico com domínio do destro sobre o canhoto, forma utilizada por $100 \%$ dos autores que utilizam esse caráter na contextualização. Apenas um autor (L1, p.55), embora cite no texto de modo semelhante aos demais, faz essa reflexão de forma apropriada, na seção "Biologia \& Cotidiano", justificando a discordância encontrada em gêmeos idênticos. De certa forma, isso pode auxiliar na desconstrução de um conceito equivocado e repetido na escola que "pais canhotos não podem ter um filho destro" e justifica a ocorrência de indivíduos ambidestros, destacado também na obra L5.

A textura do cabelo é atribuída por L4 a um padrão de herança monogênica com dominância do crespo em relação ao liso. Embora essa informação esteja presente nos exercícios, trata-se de um erro conceitual que não considera as demais texturas intermediárias, observadas na população. Esse caráter é descrito no OMIM como de base molecular desconhecida que não segue a herança mendeliana clássica, monogênica (OMIM\%139450).

A forma do lóbulo da orelha "preso ou solto" constitui um exemplo importante de padrão de herança herdado e facilmente identificado na população. Doze citações foram encontradas em cinco obras diferentes, com predominância do texto em relação aos exercícios. É consenso entre os autores atribuir esse caráter a um padrão monogênico autossômico com dominância do lóbulo solto, embora desde 1965 entende-se como improvável essa versão (OMIM 128900) em decorrência das inúmeras variações observadas no lóbulo da orelha. Uma falta de atualização bem evidente nesta situação. 
A hipertricose auricular, mesmo depois do Genoma Humano sequenciado, continua sendo um tema controverso nos livros didáticos. Citado em $71 \%$ das obras analisadas, divide-se entre autossômica com efeito limitado ao sexo (L7), ligada ao Y (L4), possível característica associada ao Y (L3) e de herança controversa, mas limitada ao sexo masculino (L1 e L6). Cabe destacar que esse caráter apresenta duas referências (OMIM 139500 e OMIM 425500), necessitando ainda de mais estudo a respeito. O encontro de mulheres com hipertricose limita as classificações dos autores e alerta com relação ao erro conceitual na descrição desse padrão de herança (Eidt, 2012).

Os genes envolvidos na produção de antígenos do sistema Rh são descritos por $87 \%$ dos livros analisados, com diferentes interpretações entre os autores. No banco de dados OMIM, a produção dos antígenos do sistema RH está atribuída a um gene para o antígeno D (RHD, OMIM 11680) e um segundo para os antígenos Cc e Ee (RHCE, OMIM 11700), localizados em direções opostas no cromossomo 1. Borges-Osório e Robinson (2013), dentre outros, descrevem a presença de mais pares de genes associados à expressão desses antígenos. Entretanto, o que se percebe nos livros, apesar de todas as informações atuais disponíveis, são erros conceituais ao atrelar esse tipo de herança a um par de genes com dominância (monibridismo) do Rh positivo e com os alelos " $\mathrm{R}$ " e " $\mathrm{r}$ " (L2, L3 e L4). Dois autores (L7 e L8) utilizam o fator Rh como exemplo de um par de genes com dominância no capítulo de monoibridismo (erro conceitual), e ao descrever os grupos sanguíneos em capítulo separado, citam a presença de poligenes (descrição apropriada) e justificam que utilizam uma simplificação para representar o alelo D (mais expresso) ou o R (dominante).

Percebe-se ainda, mesmo com todos os recursos disponíveis e possibilidades de atualizações, registros de uma multiplicidade de informações a respeito dos padrões de herança. Para o mesmo caráter, podemos encontrar descrições apropriadas, erros conceituais, desvios em relação à descrição e simplificações. Os achados mais significativos entre as formas equivocadas de descrever os padrões de herança destacam-se na sequência: erros conceituais, desvios em relação à descrição e as simplificações. Cabe salientar que foram consideradas simplificações aquelas em que o autor se posiciona a respeito da utilização delas no texto.

Nos desvios avaliados, optou-se por considerar a diferença consistente da descrição em relação aos exercícios propostos e da utilização de diferentes explicações em diferentes capítulos da mesma obra, gerando uma compreensão errada acerca do padrão de herança, ampliando as dificuldades na aprendizagem futura. Franzolin e Bizzo (2015), ao categorizarem os desvios encontrados na transposição didática do conhecimento acadêmico para o livro didático com relação aos temas meiose, Leis de Mendel e expressão gênica, descrevem os desvios conceituais como os equívocos mais comumente encontrados, caracterizados quando a descrição do processo é significativamente diferente da apresentada na referência. Neste estudo, optou-se por identificá-los como erros conceituais, visto que não estão de acordo com a referência utilizada, comprometendo a compreensão dos processos descritos. Cabe retomar que, neste estudo, o termo "desvio" foi utilizado sempre que o autor utilizou concepções diferentes a respeito do mesmo traço hereditário humano dentro da mesma obra. 
As maiores discrepâncias foram encontradas em características humanas que constituem herança poligênica, ou seja, determinadas por dois ou mais pares de genes, mas descritas como monogênica pelos autores de forma simplificada, errada ou desatualizada. Caracteres poligênicos tratados de forma monogênica buscam, muitas vezes, criar "problemas de probabilidade", a serem resolvidos como atividades de ensino de genética.

A "genética mendeliana", com a utilização de exemplos de caracteres humanos, atrai e mantém o foco dos alunos. No entanto, essas simplificações, esses desvios e erros conceituais, tanto por parte dos autores como dos que se utilizam do livro como referência, isto é, professores e alunos do Ensino Médio, levam a inconsistências no processo de aprendizagem (Baiotto, Sepel \&, Loreto, 2016). Nossa preocupação com o uso de modelos simplificados para explicar padrões de herança complexa é compartilhada por um dos autores (L1, p.41), ou citada pelos autores (L5) e (L8), que afirmam que a maioria das características humanas tem herança complexa, com influência de mais genes.

A Genética Humana é muito recente no ensino de Biologia do Ensino Médio e esteve de certa forma mais relacionada às doenças. Casagrande (2006), ao avaliar o tema "doença genética" nos livros didáticos, identificou informações descontextualizadas, desatualizadas e até incorretas. Descreve que as imagens de doenças genéticas são passadas como incapacitantes, sem tratamento e associadas a retardo mental e graves malformações físicas. Essas doenças, geralmente muito raras, estão sendo substituídas por traços hereditários mais visíveis e interessantes em termos de contextualização.

A utilização dos termos "afetado" e "normal" se constitui em outro obstáculo epistemológico no ensino de Genética. Esses termos, observados, principalmente, nas genealogias e nos exercícios, evitam equívocos com relação às doenças, cujo padrão de herança se desconhece, mas determinam problemas graves atrelados à generalização do termo "normal", bem mais difíceis de serem desconstruídos, visto que o afetado pode ser apenas um portador de um caráter qualquer.

Outra questão bastante complexa observada está atrelada ao fato de os autores das obras analisadas descreverem todos os sistemas sanguíneos dentro de um capítulo denominado "Alelos múltiplos", o que por si só já é confuso, porque todos têm um padrão de herança diferenciado. Somado a isso, L6 trata dos antígenos C, D e E (sistema Rh) como alelos múltiplos, e não como poligenes, erro conceitual grave, confundindo ainda mais os leitores.

A transposição didática somada a uma falta de atualização periódica parece ainda ser a principal responsável pelas contextualizações com erros, desvios, simplificações e demais equívocos observados. Toledo e Ferreira (2015, p.242), ao avaliarem erros conceituais em evolução e diversidade biológica, encontraram um grande número de equívocos que, segundo os autores, "podem propiciar a criação de obstáculos epistemológicos, fortalecidos pelo uso de analogias e imagens concretas no tratamento de um modelo teórico que envolve diferentes fenômenos abstratos". Eles destacam que a transposição não significa uma simplificação, e esses equívocos podem levar à compreensão errada dos conhecimentos científicos e dificuldades de aprendizagem futura. 


\section{CONSIDERAÇÕES FINAIS}

A frequência de utilização de caracteres humanos hereditários no ensino de Genética tem se ampliado de forma considerável em decorrência da necessidade de contextualizar o ensino e aproximá-lo do cotidiano, valorizando, assim, as questões sociais e culturais. Traços hereditários têm se destacado nas versões mais atuais dos livros didáticos, na contextualização do ensino, em função de que aproximam os leitores do seu dia a dia em relação a outros caracteres de animais e vegetais, distantes e pouco significativos para o aluno do Ensino Médio.

Dificuldades associadas à falta de atualização de muitos professores, problemas na transposição didática do livro para a sala de aula e da utilização do livro didático como principal referência se refletem nas inconsistências, nos desvios e equívocos encontrados com relação ao padrão de herança dos caracteres humanos, podendo se constituir em obstáculos epistemológicos, que dificultam ou entram em choque com o conhecimento científico, cultural e social discutido na sala de aula.

Os erros conceituais, os desvios em relação à descrição e o excesso de simplificações identificados nesta avaliação comprometem significativamente o ensino de genética. Podem causar o distanciamento e descrédito à disciplina em decorrência dos equívocos implícitos nessas simplificações, visto que esses traços podem ser facilmente observáveis em si mesmo e em seus familiares.

Entende-se como necessária a contextualização no ensino de Genética através da utilização dos caracteres humanos hereditários, no entanto, sugere-se maior cuidado dos autores ao utilizar simplificações e generalizações; mais atenção dos professores ao fazer a transposição didática e a contextualização no ensino; redução da utilização do livro didático como única fonte de consulta e material de aula e a utilização de metodologias diferenciadas de ensino, em que o aluno se torne o protagonista do seu processo de aprendizagem, investigando e avaliando traços hereditários humanos de herança monogênica reconhecida. Por fim, a atualização deve ser uma constante entre os professores que atuam na rede básica e entre os autores dos livros, responsáveis diretos pelo ensino de Genética a partir da implantação do PNLD.

\section{REFERÊNCIAS}

Andrade, R.O. (2016) Raízes da genética no Brasil: Ensino do mendelismo começou nas escolas de agronomia de São Paulo na década de 1910, com Carlos Teixeira Mendes. Pesquisa FAPESP, 247(91), 90-91.

Ausubel, D.P. (2003) Aquisição e retenção de conhecimentos: uma perspectiva cognitiva. Lisboa: Editora Plátano.

Badzinski, C. \& Hermel, E. E. S. (2015) A representação da genética e da evolução através de imagens utilizadas em livros didáticos de biologia. Ensaio Pesquisa em Educação em Ciências, 17(2), 434-454. doi: 10.1590/1983-21172015170208. 
Baiotto, C.R.; Sepel, L.M.N.; \& Loreto, É.L.S. (2016) Para ensinar genética mendeliana: ervilhas ou lóbulos de orelhas. Genética na Escola, 11, 286-293. Disponível em: http:// docs.wixstatic.com/ugd/b703be_2cdb152d15264daf9419bc8a9c60b654.pdf. Acesso em: 20 ago. 2017.

Bardin, L. (2011) Análise de conteúdo. São Paulo: Edições.

Bittencourt, C.M.F. (2004) Em foco: história, produção e memória do livro didático. Educação e Pesquisa, 30(3), 471-473. doi: 10.1590/S1517-97022004000300007.

Bizzo, N. (2009) Mais Ciência no Ensino Fundamental: metodologia de ensino em foco. São Paulo: Editora do Brasil.

Borges-Osório, M.R. \& Robinson, W.M. (2013) Genética humana (3a ed.). Porto Alegre: Artes Médicas, Editora da Universidade UFRGS.

Brasil. Ministério da Educação e Cultura. (2011) Secretaria de Educação Básica. Guia de Livros Didáticos: PNLD 2012 - Biologia. Brasília: MEC/SEF.

. (2008) Ministério da Educação e Cultura. Secretaria de Educação Básica. Guia de Livros Didáticos: PNLD 2012 - Biologia. Brasília: MEC/SEF.

. (2000) Ministério da Educação e Cultura. Secretaria de Educação Básica.

Parâmetros Curriculares Nacionais do Ensino Médio: Ciências da Natureza, Matemática e suas Tecnologias. Brasília: MEC/SEMTEC.

Camargo, S.S. \& Infante-Malachias, M.E. (2017) A genética humana no Ensino Médio: algumas propostas. Genética na Escola, 2(1), 14-16. Disponível em: http://docs.wixstatic. com/ugd/b703be_213a6a6514ba4157b7327c516b634d33.pdf. Acesso em: 31 ago. 2017.

Casagrande, G.L. (2006) A genética humana no livro didático de biologia. 2006. Dissertação (Mestrado em Educação Científica e Tecnológica) - Centro de Ciências Biológicas, Universidade de Santa Catarina, Florianópolis.

Chevallard, Y. (1997) La Transposición Didáctica: del saber sabio al saber enseñado. Buenos Aires: Aique.

Eidt, L. M. (2012) Manifestações dermatológicas em idosos internados e institucionalizados de Porto Alegre-RS. Tese (Doutorado em Gerontologia Biomédica) - Pontifícia Universidade Católica do Rio Grande do Sul.

Ferreira, P. \& Justi, R. S. (2005) A abordagem do DNA nos livros de biologia e química do ensino médio: uma análise crítica. Ensaio Pesquisa em Educação em Ciências, 6(1), 1415-2150. doi: 10.1590/1983-21172004060104.

Franzolin, F. \& Bizzo, N. (2015) Types of Deviation in Genetics Knowledge Presented in Textbooks Relative to the Reference Literature. Procedia - Social and Behavioral Sciences, 167, 223-228. doi: 10.1016/j.sbspro.2014.12.666.

Franzolin, F.; Tolentino-Neto, L.C.B.; \& Bizzo, N. (2014) Generalizações que distanciam os conhecimentos dos livros didáticos das referências em Genética. Investigações no Ensino de Genética. Genética na Escola, 9(2).

Gambarini, C. \& Bastos, F. (2006) A utilização do texto escrito por professores e alunos nas aulas de Ciências. In: Nardi, R.; Almeida, M.J.P. (Orgs.). Analogias, leituras e modelos no ensino da ciência: a sala de aula em estudo. São Paulo: Escrituras, 93-115.

Iinfante-Malachias, M.E.; Padilha, I.Q.M.; Weller, M.; \& Santos, S. (2010) Comprehension of basic genetic concepts by Brazilian undergraduate students. Revista Electrónica de 
Enseñanza de las Ciencias, 9(3), 657-668. Disponível em: http://reec.uvigo.es/volumenes/ volumen9/ART9_Vo19_N3.pdf. Acesso em: 21 ago. 2017.

Kato, D.S. \& Kawazaki, C.S. (2011) As concepções de contextualização do ensino em documentos curriculares oficiais e de professores de ciências. Ciência \& Educação, 17(1), 35-50. doi: 10.1590/S1516-73132011000100003.

La Rosa, J.; Ferreira, B.W.; Rodrigues, E.Z.; \& Ramos, M.B. (1998) Psicologia e educação: o significado de aprender (2a ed.). Porto Alegre: EDIPUCRS.

Lima, J.F.L.; Pina, M.S.L.; Barbosa, R.M.N.; \& Jófoli, Z.M.S. (2000) A contextualização no ensino de cinética química. Química Nova na Escola, 11, 27-29. Disponível em: http:// qnesc.sbq.org.br/online/qnesc11/v11a06.pdf. Acesso em: 18 ago. 2017.

Malafaia, G.; Bárbara, V.F.; \& Rodrigues, A.S. (2010) Análise das concepções e opiniões de discentes sobre o ensino da biologia. Revista Eletrônica de Educação, 4(2), 165-182. doi: 10.14244/1982719994.

Moura, J. et al. (2013) Biologia/genética: o ensino de biologia, com enfoque a genética, das escolas públicas no Brasil - breve relato e reflexão. Semina: Ciências Biológicas e da Saúde, 34(2),167-174. doi: 10.5433/1679-0367.2013v34n2p167.

Lopes, A.C. (2002) Os parâmetros curriculares nacionais para o ensino médio e a submissão ao mundo produtivo: o caso do conceito de contextualização. Educação \& Sociedade, 23(80), 386-400. doi: S0101-73302002008000019.

Loreto, É.L.S. \& Sepel, L.M.N. (2003) A escola na era do DNA e da Genética. Ciência e Ambiente, 26, 149-156.

Melo, J.R. \& Carmo, E.M. (2009) Investigações sobre o ensino de genética e biologia molecular no ensino médio brasileiro: reflexões sobre as publicações científicas. Ciência \& Educação, 15(3). doi: 10.1590/S1516-73132009000300009.

Novak, J.D. (2011) Uma teoria de educação: aprendizagem significativa subjacente à integração construtiva de pensamentos, sentimentos e ações levando ao empoderamento para compromisso e responsabilidade. Aprendizagem Significativa em Revista/Meaningful Learning Review, 1(2), 1-14. Disponível em: http://www.if.ufrgs.br/asr/artigos/Artigo ID7/v1_n2_a2011.pdf.Acesso em:28 ago. 2017.

Online Mendelian Inheritance in Man (OMIM) (2017) An Online Catalog of Human Genes and Genetic Disorders. Disponível em: http://www.omim.org/. Acesso em: 30 ago. 2017.

Paiva, A L B. \& Martins, C.M.C. Concepções prévias de alunos de terceiro ano do Ensino Médio a respeito de temas na área de Genética. Ensaio Pesquisa em Educação em Ciências, 7(3), 182-201. doi: 10.1590/1983-21172005070303.

Pimentel, J.R. (1998) Livros didáticos de Ciências: a Física e alguns problemas. Caderno Catarinense de Ensino de Física, 15(3), 308-318. doi: 10.5007/\%25x.

Santos, V.C. \& El-Hani, C.N. (2009) Ideias sobre genes em livros didáticos de biologia do ensino médio publicados no Brasil. Revista Brasileira de Pesquisa em Educação em Ciências, 9(1).

Scheid, N.M.; Ferrari, N. (2006) A história da ciência como aliada no ensino de genética. Genética na Escola, 1(1), 17-18. Disponível em: http://docs.wixstatic.com/ugd/b703be 6418c0f6af7d445bbd186c47852833e5.pdf. Acesso em: 26 jul. 2017. 
Soares, K.C.; Pinto, M.C.; Rocha, M.O. (2005) Cada lócus por si mesmo: por onde andam esses genes? Genética na sala de aula: estratégias de ensino e aprendizagem. Rio de Janeiro: PROMED/UFRJ.

Souza, V.S. et al. (2013) História da genética no Brasil: um olhar a partir do Museu da Genética da Universidade Federal do Rio Grande do Sul. Fontes, 20(2), 675-694.

Strachan, T. \& Read, A. (2013) Genética molecular humana. Tradução de A. B. Marisini et al. (4a ed.). Porto Alegre: Artmed.

Toleto, E.J.L. \& Ferreira, L.H. (2015) Transposição didática como reforço de obstáculos epistemológicos em livro texto e em experimentos didáticos. Revista Electrónica de Enseñanza de las Ciencias, 14(2). Disponível em: http://reec.uvigo.es/volumenes/ volumen14/REEC_14_2_6_ex964.pdf. Acesso em 27 jul. 2017.

Vigostski, L.S. (2001) A construção do pensamento e da linguagem. São Paulo: Martins Fontes. 